\title{
Language Learning Strategies as Used by Saudi Students at Majmaah University
}

\author{
Sami Hussein A. Ahmed ${ }^{1 \& 2}$ \\ ${ }^{1}$ Department of English, College of Education, Majmaah University, Majmaah 11952, Saudi Arabia \\ ${ }^{2}$ Department of English, College of Languages, University of the Holy Quran \& Islamic Sciences, Sudan \\ Correspondence: Sami Hussein A. Ahmed, Department of English, College of Education, Majmaah University, \\ Majmaah 11952, Saudi Arabia. E-mail: S.abdelrhman@mu.edu.sa or samihussein40@hotmail.com
}

Received: June 2, $2020 \quad$ Accepted: November 16, $2020 \quad$ Online Published: November 23, 2020

doi:10.5539/ijel.v11n1p147 URL: https://doi.org/10.5539/ijel.v11n1p147

\begin{abstract}
This paper examines the patterns of the primary language learning strategies practiced by Saudi students. It investigates the correlation between students' language competence and their choice of strategy. The study employed a questionnaire focussing on participants' self-assessment of their linguistic proficiency, i.e., the Strategy Inventory of Language Learning (SILL) by Oxford (1990). This is made up of fifty self-assessment items assessing learners' regularity in their use of specific language strategies. The outcome reveals that, of the six types of language learning strategies, students tend to most frequently employ the metacognitive strategy, followed by cognitive and social strategies. The findings also highlight that students in possession of a high level of English proficiency are closely associated with the use of: (1) two compensation strategies; (2) two metacognitive strategies; and (3) one effective strategy.
\end{abstract}

Keywords: language learning strategies, use, level, SILL

\section{Introduction}

A considerable degree of research has recently been undertaken into methods capable of assisting students when learning a foreign language (Rubin, 1987; Oxford, 1990). Researchers have also attempted to analyze factors influencing the choice of Language Learning Strategies (LLSs) (i.e., Oxford \& NcKos, 1989), concluding that students who are highly motivated tend to prove more successful in acquiring a foreign language than those who remain lacking in motivation. In addition, these researchers examined how LLSs are employed by effective language learners to assist their peers in adopting strategies beneficial for improving their language competence. The current researcher undertook a similar study in the context of Saudi Arabia. The aim was to: firstly, scrutinize the most popular LLS used by Saudi students and secondly, to explore the relationship between the different levels of English language competency on a student's choice of language strategy and general practice.

\subsection{Research Questions}

1) What kinds of LLS are generally to be practiced by Saudi students?

2) To what extent does the level of English competence influence the students' selection of language strategy and the frequency of use?

\section{Theoretical Framework}

Language strategies consist of a set of processes used by learners to acquire a language, including: (1) recall; (2) memorization; and (3) use (Rigency, 1978). Oxford (1990) noted that language strategies originate from specific operations that facilitate learning by making it enjoyable and self-managed and are also transferable to a more complex set of circumstances. Stern (1992) considered this concept to be based on the hypothesis that students deliberately become involved in certain actions in order achieve specific objectives. Hence, learning strategies can be considered as internal motivation and learning techniques.

Rubin (1987) classified LLS into three categories:

a. Learning strategies.

b. Communication strategies. 


\section{c. Social strategies.}

These are further subcategorized as follows:

1) Communication Strategies: These are practiced by language learners in order to be able to hold fluent conversations.

2) Social strategies: These are indirect strategies that, instead of focussing on recalling, memorizing and practicing the language, assist learners to interact with the target community language. They offer opportunities to learners to become exposed to the culture of the native speakers.

3) Affective strategies: These consist of actions taken by learners in order to motivate themselves to address their emotional issues, and so reduce their anxiety.

\section{Related Literature}

Rao (2016) found that the language skills of students greatly influenced the use of their learning technique, and also noted that high-level students provide more techniques than low-level students.

Tests obtained significant use scores by the teachers and the learners' medium use, but both classes registered the most regularly used metacognitive strategies. Gavriilidou et al. (2017), who reached the same conclusion with respect to metacognitive strategies, inspected elementary and secondary Muslim EFL students and their teachers' tactical profiles to study the point of intersection in their plan of action used by students and promotion by teachers. Given that both experiments were performed concurrently and within the same academic context, this correlation was somewhat anticipated considering established social gaps amongst conventional and EFL students of the Muslim community. Even then, the two experiments did not overlap in the sequence of the choice of the students with respect to the other groups that might reflect variations in the spectrum of academic objectives between the two forms of learning.

Amir yousefi (2015) examined the convictions of 320 adult EFL Iranian pupils from primary to elite courses and 72 English teachers about the effectiveness of vocabulary knowledge, while students and teachers widely understood in their views, the utility of such memorization techniques was somewhat divided. Depending on the academic background, variations of interpretation about vocabulary strategies have also been found.

M. Platsidou et al. (2017) also examined certain individual characteristics, such as instructor age, academic status and postgraduate studies, when focusing on the phases of growth of the teacher' survey (the key element in the current study). The findings indicate that older teachers reported education policies that encouraged cognitive strategies more often compared to their younger colleagues, and educators of primary education identified using methods that supported memory strategies, while educators with postgraduate studies supported social strategies promotion. Blasiman et al. (2017) found that it is not evident on what grounds students select those methods, how they use methods and why they have a bias over others, although a great deal of research has established factors that may influence the study methods of students.

$\mathrm{Li}$ and Zhang (2018) had used meta-analysis to explain the relation among language learning strategies and English learning performance focusing on 41 studies published in China, involving 48 samples collected. The findings showed that six factors of SILL are positively correlated with English proficiency, with the substantial beneficial impact varying from small to medium. In reality, learning methods are often connected with the final outcome of the pupils. Assessing the techniques of pupils and their impact on academic success helps one to identify how pupils manage various activities, which tactics they use for particular assignments, and which technique they can adopt to learn better.

Similarly, a significant amount of observational findings showed that students' forms of learning methods were strongly compatible with their cognitive styles. A research done by Hsu and Chen (2016) found that involved, thoughtful and stable learner styles in social, memory, and metacognitive strategies influence their choices.

Furthermore, studies have indicated a number of differences between the sexes when it comes to language learning methods. For example, Hong-Nam and Leavell (2006) investigated the use of learning strategy of fifty-five students learning English as a Second Language (ESL), who had different linguistic and cultural backgrounds, including: Brazil; Togo; China; Taiwan; Korea; Germany; Indonesia; Japan; Thailand; and Malaysia. The findings revealed that the students tended to favor metacognitive approaches (i.e., those structured to encourage students to 'think' about their 'thinking'), but made less use of approaches such as affective and memory in the overall strategy. This implies that the students disliked dealing with their emotions and therefore used techniques to improve their working memory and access their long-term memory.

However, Grenfell and Harris (2015) note, there is no LLS in a vacuum, and studies have demonstrated that 
learners' desire for one category or another is affected by complicated and numerous individual and contextual variables, such as age, skill and gender, have been widely examined from the very first LLS findings. Senior students were also reported to use a wider variety of LLS and a different mentality compared with younger students.

\section{Methodology of the Study}

\subsection{The Study Instruments}

This study employed a questionnaire following the self-reported language proficiency scale drawn up by Oxford (1990).

This SILL enlisted fifty self-assessment queries relevant to the use of strategy for learning a language. Participants were required to answer on a five-point Likert scale commencing.

The SILL consisted of dual major bodies of three strategies, each noted consecutively:

1) Direct strategies: memory strategies, cognitive strategies and compensation strategy.

2) Indirect strategies: metacognitive strategies and social strategies.

\subsection{Subjects}

The participants of this study consisted of twenty-seven male students of various different language levels (First, second, third, and fourth year, i.e. first and second years are considered lower levels while third \& fourth years are higher levels), who were enlisted in the Department of English. Students were chosen randomly.

\subsection{Findings}

This part presents data findings obtained from the questionnaire. It comprises 50 items grouped into six categories: (a) memory strategies (9 items); (b) cognitive strategies (14 items); (c) compensation strategies (6 items); (d) metacognitive strategies (9 items); (e) affective strategies (6 items); and (f) social strategies (6 items).

Table 1. The general practice of strategies

\begin{tabular}{lll}
\hline Strategy & Mean & SD \\
\hline Metacognitive & 4.19 & 0.60 \\
Cognitive & 3.81 & 0.64 \\
Social & 3.81 & 0.64 \\
Memory & 3.62 & 0.73 \\
Compensation & 3.76 & 0.71 \\
Affective & 3.23 & 0.78 \\
\hline
\end{tabular}

Table 1 demonstrates that students who more regularly practiced metacognitive strategies were recorded more frequently than the other types of English learning strategies, with a mean of 4.19. A lower number were recorded using cognitive and social strategies, with a mean of $=3.81$, followed by memory strategy (Mean $=$ 3.62 ) then compensation strategies (Mean = 3.76) and affective strategy ("Mean = 3.23").

In addition, advanced students were found to be making considerable use of two metacognitive strategies and one effective strategy. For example, students demonstrating a superior ability in English recorded an ability to use body language, due to not needing to concentrate on seeking the correct expression while speaking. This also highlights that students in possession of high levels of proficiency were able to recognize their errors and locate the information to ensure they improved. They were also able to identify methods of improving their competence in English. Advanced level students were inclined to discuss their experiences and emotions related to the process of learning English.

\subsection{Analysis}

Q 1: What kinds of LLS are generally to be practiced by Saudi students?

The study found that students who more regularly practiced metacognitive strategies were recorded more frequently than the other types of English learning strategies. The current participants were not found to practice effective and memory strategies to a great extent and memory strategies were the least employed by students, possibly as learners are able to omit fundamental aspects, i.e., lexical words and grammatical rules. It also identified that learners continue to reduce their use of memory strategies as they become more involved in effective control of alternative LLS. This outcome is similar to the findings of Hong-Nam and Leavel (2006), 
who discovered that students' least popular strategies were effective strategies and memory strategies. These learners demonstrated an attempt to gain in confidence and overcome their hesitancy when it came to communicating in English, but were prevented by anxiety that they might commit an error. This can prove a particular issue for students from communities that place an emphasis on keeping face, leading to a fear of losing the respect of others and so an unwillingness to take risks.

Q2: To what extent does the level of English competence influence the students' selection of language strategy and the frequency of use?

As noted above, the analysis of the students' levels of English proficiency were related to two compensation strategies, two metacognitive strategies and one affective strategy. This outcome accords with the findings of Gavriilidou et al. (2017), who reached the same conclusion with respect to metacognitive strategies, inspected elementary and secondary Muslim EFL students and their teachers' tactical profiles to study the point of intersection in their plan of action used by students and promotion by teachers.

In connection with this finding, Rao (2016) found that the language skills of students greatly influenced the use of their learning technique, and also noted that high-level students provide more techniques than low-level students.

The study also exhibited that advanced learners tend to make more use of compensation and metacognitive strategies and are thus more tactical when it comes to language learning. The findings can thus be seen to make a noteworthy contribution to the subject, since the improvement of efficiency has been identified as the most decisive aspect of promoting feelings of self-adequacy among Non-native English Speaking Teachers (NNESs).

Likewise, Li and Zhang (2018) had used meta-analysis to explain the relation among language learning strategies and English learning performance focusing on 41 studies published in China, involving 48 samples collected. The findings showed that six factors of SILL are positively correlated with English proficiency, with the substantial beneficial impact varying from small to medium. In reality, learning methods are often connected with the final outcome of the pupils. Assessing the techniques of pupils and their impact on academic success helps one to identify how pupils manage various activities, which tactics they use for particular assignments, and which technique they can adopt to learn better.

Students' choice of strategies was not limited solely to their language level, but also to a number of other aspects. Grenfell and Harris (2015) note, there is no LLS in a vacuum, and studies have demonstrated that learners' desire for one category or another is affected by complicated and numerous individual and contextual variables, such as age, skill and gender, have been widely examined from the very first LLS findings. Senior students were also reported to use a wider variety of LLS and a different mentality compared with younger students.

\section{Conclusion}

This paper explored LLS as practiced by Saudi students. It investigated the relationship between a student's proficiency in English and his/her use of alternative language strategies, along with the generality of practice. The research employed a questionnaire examining participants' self-assessment of their language proficiency. This paper argues that students generally tend to make more use of metacognitive strategies than the other five kinds of English learning strategies, followed by cognitive and social strategies. The research identified that a student's proficiency level in English can be associated with two compensation strategies and one effective strategy. The study also exhibited that capable learners tend to practice compensation and metacognitive strategies and are tactical when it comes to their future language learning. In general, this paper concludes that a larger number of capable students make a greater, and more productive, use of an extensive range of LLS.

\section{Limitations}

The findings of this study should be viewed with caution, due to the followings: Firstly, the small number of students result in the findings remaining inconclusive, thus highlighting the need for further research to examine a larger group of participants. Secondly, it would be beneficial for further research to assess whether students from different linguistic backgrounds make effective use of learning methods.

The research also needs to acknowledge a drawback in the use of SILL to produce LLS, as this needs to be complemented with various other testing tools and methods, including: (1) think-aloud procedures consistent with interviews; (2) written diaries; and (3) a number of other approaches promoting the practical use of strategies and more sample-specific details. Furthermore, as stated earlier, it is likely that defined learning strategies may be influenced by a number of additional factors, i.e., ethnicity, age and area of study. This highlights the need for future studies to incorporate multiple methodologies capable of corroborating and validating the results arising from the use of SILL as a primary instrument. 


\section{References}

Amir, Y. M. (2015). Iranian EFL learners' and teachers' beliefs about the usefulness of vocabulary learning strategies. SAGE Open. https://doi.org/10.1177/2158244015581382

Blasiman, R. N., Dunlosky, J., \& Rawson, K. A. (2017). The what, how much, and when of study strategies: Comparing intended versus actual study behaviour. Memory, 25, 784-792. https://doi.org/10.1080/09658211.2016.1221974

Gavriilidou, Z. et al. (2017). Profiling learners' strategy use and teachers' strategy promotion in minority primary and secondary schools: Implications for foreign language teaching. In Z. Gavriilidou, K. Petrogiannis, M. Platsidou \& A. Psaltou-Joycey (Eds.), Language Learning Strategies: Theoretical Issues and Applied Perspectives (pp. 124-147). Kavala: Saita Publications.

Grenfell, M., \& Harris, V. (2015). Modern languages and learning strategies in theory and practice. London: Routledge.

Hong-Nam, K., \& Leavell, A. (2006). Language learning strategy use of ESL students in an intensive English learning context. System, 34(3), 399-415. https://doi.org/10.1016/j.system.2006.02.002

Hsu, C. W., \& Chen, S. C. (2016). A study of EFL college students' learning styles and learning strategies. Journal of Modern Education Review, 6(1), 1-9. https://doi.org/10.15341/jmer(2155-7993)/01.06.2016/001

Li, W., \& Zhang, J. (2018). A meta-analysis of the correlations in SILL based studies on Chinese university students' language learning strategies and English learning achievement in China. Foreign Language Learning Theory and Practice, 164(4), 41-49.

Oxford, R. L. (1990). Language learning strategies: What every teacher should know. New York: Newbury House.

Oxford, R. L., \& Nyikos, M. (1989). Variables affecting choice of language learning strategies by university students. The Modern Language Journal, 73(3), 291-300. https://doi.org/10.1111/j.1540-4781.1989.tb06367.x

Platsidou, M. et al. (2017). Foreign language teachers' strategy instruction practices in Greek lower secondary education. In Z. Gavriilidou, K. Petrogiannis, M. Platsidou \& A. Psaltou-Joycey (Eds.), Language Learning Strategies: Theoretical Issues and Applied Perspectives (pp. 96-123). Kavala: Saita Publications.

Rao, Z. (2016). Language learning strategies and English proficiency: interpretations from information-processing theory. Lang. Learn. J., 44, 90-106.

Rigney, J. W. (1978). Learning strategies: A theoretical perspective. In H. F. O’Neil Jr. (Ed.), Learning Strategies (pp. 165-205). Academic Press, New York.

Rubin, J. (1987). Learner strategies: Theoretical assumptions, research history and typology. In A. Wenden \& J. Rubin (Eds.), Learner strategies in language learning (pp. 15-29). Englewood Cliffs, NJ: Prentice Hall.

Stern, H. H. (1992). Issues and options in language teaching. Oxford: OUP.

Teh, K., Embi, M., Yusoff, N., \& Mahamod, Z. (2009). A closer look at gender and Arabic language learning strategies use. European Journal of social Sciences, 9(3), 399-407.

\section{Copyrights}

Copyright for this article is retained by the author, with first publication rights granted to the journal.

This is an open-access article distributed under the terms and conditions of the Creative Commons Attribution license (http://creativecommons.org/licenses/by/4.0/). 